\title{
PENINGKATAN PENDAPATAN PETANI KARET MENGGUNAKAN CABAI RAWIT (Capsicum frutescens Linn.) SEBAGAI TANAMAN SELA (Studi Kasus Di Desa Sembawa, Kecamatan Sembawa, Provinsi Sumatera Selatan)
}

The Enhanced Income of Smallholder Using Cayenne Pepper (Capsicum frutescen Linn.) as Intercrops (Case Study in Sembawa Village, Sembawa District, South Sumatra Province)

\section{Sahuri}

Balai Penelitian Sembawa, Pusat Penelitian Karet, Palembang 30001, Indonesia

*Corresponding author: sahuri_agr@ymail.com

\section{ABSTRACT}

One alternative effort in order to increase the income of smallholders on immature rubber period was by practicing rubber based mix-cropping with other supporting plants. This research was conducted to observe the growth of girth and the enhanced income of smallholder using cayenne pepper as intercrops with the application of recommendation technology. This study was carried in dry land between rubber trees in Sembawa Village, Sembawa District, South Sumatra from June until October 2014. The treatment was of recommended technologies and farmer's technologies. The results showed that the application of recommended technologies was significant effect on rubber growth, number of branches, fresh fruit production/plant, and fresh fruit production/1000 $\mathrm{m}^{2}$ ha except for plant height and harvesting time. However, overall the recommendation technology was better than farmer technology. Production of fresh fruit at $650,5 \mathrm{~kg} / 1000 \mathrm{~m}^{2}$ higher than farmer technology by $348,9 \mathrm{~kg} / 1000 \mathrm{~m}^{2}$. Gains derived by application of cayenne pepper farming technology recommended by IDR 5.456.000/1000 $\mathrm{m}^{2}$ larger than IDR 2.704.200/1000 $\mathrm{m}^{2}$ farmer technology with the B/C ratio of 1.27 and farming is feasible to be developed with MBCR value of 1.55 .

Key words : Hevea brasiliensis, cayenne pepper, intercrops, income, smallholders

\begin{abstract}
ABSTRAK
Salah satu alternatif untuk meningkatkan pendapatan petani karet pada masa tanaman belum menghasilkan (TBM) adalah adanya komoditas pendukung yang diusahakan secara mix-cropping dengan tanaman karet. Penelitian ini bertujuan mengetahui peningkatan pendapatan petani karet menggunakan cabai rawit sebagai tanaman sela dengan penerapan teknologi anjuran dan pengaruhnya terhadap pertumbuhan karet. Perlakuan membandingkan teknologi anjuran dan teknologi petani. Penelitian dilaksanakan pada lahan kering di antara tanaman karet, di Sembawa, Sumatera Selatan pada bulan Juni sampai Oktober 2014. Parameter agronomis tanaman karet dan cabai rawit dianalisis dengan uji-t dan nilai usahatani cabai rawit dengan $\mathrm{B} / \mathrm{C}$ ratio. Hasil menunjukkan bahwa penerapan teknologi anjuran berpengaruh nyata terhadap pertumbuhan lilit batang karet, jumlah cabang, bobot/buah, produksi buah segar/tanaman, produksi buah segar/1000 $\mathrm{m}^{2}$, kecuali tinggi tanaman dan umur panen cabai rawit. Namun, secara keseluruhan teknologi anjuran lebih baik daripada teknologi petani. Produksi buah segar sebesar 650,5 kg/1000 m² lebih tinggi dibandingkan teknologi petani sebesar 348,9 kg/1000 $\mathrm{m}^{2}$. Keuntungan yang diperoleh usahatani cabai rawit dengan penerapan teknologi anjuran sebesar Rp 5.456.000/1000 $\mathrm{m}^{2}$ lebih
\end{abstract}


besar daripada teknologi petani $\mathrm{Rp}$ 2.704.200/1000 $\mathrm{m}^{2}$ dengan nilai $\mathrm{B} / \mathrm{C}$ ratio 1,27 dan usahatani tersebut layak untuk dikembangkan dengan nilai MBCR 1,55.

Kata kunci : Hevea brasiliensis, cabai rawit, tanaman sela, pendapatan, petani karet

\section{PENDAHULUAN}

Petani karet rakyat masih memiliki tingkat pendapatan rumah tangga yang rendah. Hal ini disebabkan oleh (1) hasil produksi karet dan harga jual mengalami penurunan dan (2) modal usaha yang terbatas. Oleh karena itu perlu komoditas pendukung yang diusahakan secara mix-cropping dengan tanaman karet (Zainol et al., 1993; Wibawa dan Rosyid, 1995; Pribadi, 2003; Rodrigo et al., 2004; Acquaah, 2005; Rosyid, 2007; Xianhai et al., 2012).

Pemeliharaan tanaman karet belum menghasilkan (TBM) berpengaruh terhadap produksi lateks, ditinjau dari pemberian pupuk untuk mensuplai hara tanaman dan pemanfaatan lahan melalui penanaman tanaman sela. Selain itu, penanaman tanaman sela juga dapat mengurangi kompetisi tanaman karet dengan gulma. Pada umumnya tanaman sela diusahakan selama tiga tahun masa TBM (Weifu et al., 1999; Anwar, 2001; Rodrigo et al., 2001; Adri et al., 2005; Wibawa et al., 2006; Syawal, 2010; Snoeck et al., 2013; Sahuri dan Rosyid, 2015), sehingga berpotensi dimanfaatkan untuk budidaya tanaman sela.

Salah satu tanaman yang dapat dibudidayakan di antara tanaman karet TBM adalah cabai rawit. Cabai rawit adalah salah satu komoditas hortikultura unggulan yang banyak diusahakan oleh petani. Komoditas ini merupakan sumber pendapatan dan kesempatan kerja yang memberikan kontribusi cukup tinggi terhadap perkembangan ekonomi wilayah. Lokasi produksinya tersebar cukup luas, baik dataran rendah maupun dataran tinggi dan dapat ditanam pada musim penghujan maupun musim kemarau (Moekasan et al., 2011). Menurut Badan Pusat Statistik (2011), produktivitas cabai nasional Indonesia tahun 2010 adalah 5.6 ton/ha. Angka tersebut masih sangat rendah jika dibandingkan dengan potensi produksinya. Menurut Syukur et al. (2010) potensi cabai rawit nasional dapat mencapai 10 - 12 ton/ha.

Pola tanam cabai rawit sebagai tanaman sela karet pada umumnya diusahakan oleh petani di daerah-daerah yang dekat dengan pasar atau perkotaan yang berorientasi pasar. Hal ini karena tanaman cabai memiliki prospek yang cukup baik dan menguntungkan bagi usahatani karet. Keuntungan menanam cabai sebagai tanaman sela karet adalah : 1) dapat memenuhi kebutuhan pangan bagi petani; 2) dapat meningkatkan pendapatan; 3) meningkatkan intensitas pemeliharan kebun karet; 4) sebagai penutup tanah untuk mengurangi bahaya erosi dan perkembangan gulma; 5) sebagai sumber bahan organik tanah, dan 6) meningkatkan intensitas kunjungan dan pemeliharaan kebun karet oleh petani (Rosyid, 2007 dan Prasetyo et al., 2009).

Usaha peningkatan produktivitas cabai rawit sangat perlu dilakukan untuk memenuhi permintaan yang semakin meningkat. Benih bermutu dari varietas unggul merupakan salah satu faktor yang mempengaruhi keberhasilan produksi cabai rawit. Salah satu upaya untuk meningkatkan produksi dan kualitas hasil cabai rawit adalah melalui program optimalisasi lahan melalui teknologi pola usahatani tanaman cabai rawit sebagai tanaman sela karet. Penelitian ini bertujuan mengetahui pertumbuhan lilit batang karet dan peningkatan pendapatan petani karet menggunakan cabai rawit sebagai tanaman sela dengan penerapan teknologi anjuran.

\section{BAHAN DAN METODE}

Penelitian dilaksanakan di lahan kering dataran rendah pada kebun karet di Desa Sembawa, Kecamatan Sembawa, Provinsi 
Sumatera Selatan pada bulan Juni sampai Oktober 2014. Penggkajian dibuat plot dalam bentuk On Farm Research (OFR) membandingkan antara teknologi anjuran dan teknologi petani masing-masing seluas 1000 $\mathrm{m}^{2}$. Komponen teknologi anjuran terdiri dari: penggunaan varietas unggul Bara $(960 \mathrm{M} \mathrm{x}$ 960 F), klon karet anjuran PB 260, dolomit, pupuk kandang, pupuk dasar (N, P, K), pupuk daun, jarak tanam, sistem tanam, dan pengendalian organisme pengganggu tanaman (OPT) (Tabel 1). Penentuan petani non kooperator dengan metode survey lapangan secara purposive sampling.
Data agronomis karet adalah pertumbuhan lilit batang tanaman karet $(\mathrm{cm})$ pada umur 4, 8, 12, 16, 20 dan 24 bulan setelah tanam (BST) $100 \mathrm{~cm}$ dari pertautan okulasi (dpo). Jumlah contoh tanaman karet yang diamati adalah 30 tanaman karet dari teknologi anjuran dan 30 tanaman karet dari teknologi petani. Data agronomis cabai rawit adalah tinggi tanaman, umur panen, jumlah cabang, bobot/buah, produksi buah segar/tanaman, produksi buah segar $/ 1000 \mathrm{~m}^{2}$. Jumlah contoh tanaman cabai rawit yang diamati adalah 30 tanaman dari teknologi anjuran dan 30 tanaman dari teknologi petani.

Tabel 1. Komponen teknologi anjuran dan cara petani budidaya cabai rawit sebagai tanaman sela karet

\begin{tabular}{|c|c|c|}
\hline Komponen Teknologi & Teknologi anjuran & Teknologi cara petani \\
\hline Varietas cabai rawit & Bara (960 M x 960 F), berlabel/bermutu & lokal, turunan \\
\hline Persiapan Lahan & $\begin{array}{l}\text { Tanah diolah }+ \text { bedengan dengan ukuran } \\
\text { lebar } 100 \mathrm{~cm} \text { dan tingginya } 50 \mathrm{~cm}\end{array}$ & $\begin{array}{l}\text { Tanah diolah }+ \\
\text { bedengan tidak ada ukuran }\end{array}$ \\
\hline Pengapuran & Dolomit 2 ton/ha diberikan sebelum tanam & Tidak pakai \\
\hline Pupuk Kandang & $\begin{array}{l}\text { Kotoran ayam dosis } 10 \text { ton/ha diberikan } \\
\text { sebelum tanam }\end{array}$ & $500 \mathrm{~kg} / \mathrm{ha}$ \\
\hline Penanaman & $\begin{array}{l}\text { Jarak guludan dari tanaman karet } 1 \mathrm{~m} \text {. Jarak } \\
\text { tanam cabai } 60 \mathrm{~cm} \times 40 \mathrm{~cm}, 1 \text { minggu } \\
\text { setelah tanam dilakukan penyulaman, jarak } \\
\text { tanam karet } 6 \mathrm{~m} \times 3 \mathrm{~m} .\end{array}$ & $\begin{array}{l}\text { Jarak guludan dari tanaman karet } 50 \mathrm{~cm} \text {. Jarak } \\
\text { tanam cabai } 20 \mathrm{~cm} \text { x } 40 \mathrm{~cm}, 1 \text { minggu setelah } \\
\text { tanam tidak dilakukan penyulaman, jarak } \\
\text { tanam karet } 6 \mathrm{~m} \times 3 \mathrm{~m} .\end{array}$ \\
\hline Pupuk dasar (kg/ha) & $\begin{array}{l}200 \mathrm{~kg} \text { urea (diberikan } 50 \mathrm{~kg} / \mathrm{ha} \text { saat tanam, } \\
50 \mathrm{~kg} / \mathrm{ha} 2 \text { minggu setelah tanam (MST), } \\
\text { dan } 100 \mathrm{~kg} / \mathrm{ha} 1 \text { bulan setelah tanam (BST) } \\
\text { dan } 150 \mathrm{~kg} \text { SP36 (diberikan saat tanam), } \\
\text { dan } 150 \mathrm{~kg} \mathrm{KCl}(50 \mathrm{~kg} / \mathrm{ha} \text { saat tanam, } 100 \\
\mathrm{kg} / \mathrm{ha} 2 \mathrm{MST} \text { ) }\end{array}$ & $100 \mathrm{~kg}$ urea, $50 \mathrm{~kg} \mathrm{KCl}$, dan $50 \mathrm{~kg} \mathrm{SP} 36$ \\
\hline Pupuk daun & Bayfolan 2 gr/lt air & Tidak pakai \\
\hline Penyiangan & $\begin{array}{l}\text { Penyiangan pertama pada } 15 \mathrm{HST} \text { dan } \\
\text { penyiangan kedua pada } 28-30 \mathrm{HST} \\
\text { tergantung kondisi lapangan. }\end{array}$ & Kadang-kadang \\
\hline $\begin{array}{l}\text { Pengendalian Hama dan } \\
\text { Penyakit }\end{array}$ & $\begin{array}{l}\text { Sistem monitoring dan pengendalian penyakit } \\
\text { bulai dengan ridomil dan hama lalat buah } \\
\text { dengan Furadan } 3 \mathrm{G}\end{array}$ & Kadang-kadang \\
\hline
\end{tabular}

Plot pengkajian teknologi anjuran dan teknologi petani menggunakan karet TBM klon PB 260 tahun tanam 2013. Jarak tanam karet yang digunakan adalah $6 \mathrm{~m} \times 3 \mathrm{~m}$ (populasi 550 tanaman/ha.
Data input-output usahatani pola intercropping karet+cabai rawit diperoleh dari pengamatan langsung dilapangan membandingkan antara teknologi anjuran dan teknologi petani. 
Data agronomis tanaman karet dan cabai rawit dianalisis secara statistik dengan uji-t (Gomez and Gomez, 1995) dengan program statistik SAS 9.0. Analisis usahatani cabai rawit sebagai tanaman sela karet menggunakan metoda input-output analisis menampilkan $B / C$ ratio (Soekartawi, 1995), sebagai berikut:

$$
\begin{aligned}
& \mathrm{I}=\mathrm{TP}-\mathrm{TB} \\
& \mathrm{I}=(\mathrm{Q} \cdot \mathrm{Pq})-\mathrm{TB}
\end{aligned}
$$

$$
\begin{aligned}
& \text { (Q.Pq) - TB } \\
& \mathrm{B} / \mathrm{C} \text { ratio }= \\
& \text { TB }
\end{aligned}
$$

Keterangan:

$\begin{array}{ll}\mathrm{I} & =\text { Income/ Pendapatan }(\mathrm{Rp}), \\ \mathrm{TP} & =\text { Total Penerimaan }(\mathrm{Rp}), \\ \mathrm{TB} & =\text { Total Biaya }(\mathrm{Rp}), \\ \mathrm{Pq} & =\text { Harga per unit produksi }(\mathrm{Rp} / \mathrm{kg}), \\ \mathrm{Q} & =\text { Produksi/ output }(\mathrm{kg}) .\end{array}$

Nilai $\mathrm{B} / \mathrm{C}$ ratio $=$ Nisbah pendapatan terhadap pengeluaran, dengan keputusan $B / C$ Ratio > 1 usahatani menguntungkan, $B / C$ Ratio $=1$ usahatani berada pada titik impas, dan $B / C$ Ratio< 1 usahatani tidak menguntungkan. Tingkat kelayakan teknologi dilakukan analisis marginal benefit cost ratio (MBCR), yaitu: MBCR = Pendapatan usahatani pola perbaikan dikurangi pendapatan usahatani pola petani dibagi dengan biaya usahatani pola perbaikan dikurangi biaya usahatani pola petani.

\section{HASIL DAN PEMBAHASAN}

\section{Teknologi Anjuran Usahatani Cabai Rawit Sebagai Tanaman Sela Karet}

Perbaikan teknologi untuk meningkatkan produktivitas cabai rawit sebagai tanaman sela karet yaitu penggunaan varietas unggul, pengolahan lahan dengan pembuatan bedengan, pengapuran, pengaturan jarak tanam, cara tanam, pemupukan (pupuk kandang ayam, pupuk dasar urea, SP-36, $\mathrm{KCl}$, pupuk daun, dan pengendalian organisme pengganggu tanaman (OPT) yang disesuaikan dengan teknologi anjuran budidaya cabai rawit sebagai tanaman sela karet terdapat pada (Tabel 1).

Penggunaan varietas cabai rawit unggul merupakan kunci utama untuk memperoleh hasil cabai yang tinggi. Kriteria benih cabai rawit yang digunakan pada pola tanam cabai sebagai tanaman sela karet adalah berdaya kecambah tinggi > 80\%, mempunyai vigor yang baik, murni tidak tercampur oleh varietas lain dan sehat bebas OPT. Selain itu, beradaptasi dengan baik di dataran rendah sampai tinggi dengan ketinggian 150 - 1.050 meter dari permukaan laut (dpl).

\section{Pertumbuhan Lilit Batang Karet}

Dinamika pertumbuhan lilit batang karet dari pengamatan umur 4 - 12 bulan berdasarkan hasil analisis regresi pertumbuhan lilit batang karet menggunakan teknologi anjuran lebih besar dibandingkan dengan teknologi petani (Tabel 2). Pertumbuhan lilit batang karet pada teknologi anjuran intercropping karet+cabai lebih besar dibandingkan dengan teknologi petani. Hal ini karena adanya input hara yang lengkap seperti pupuk anorganik, pupuk daun, dan pupuk kandang ayam saat pemeliharaan tanaman cabai rawit. Produksi cabai rawit dengan teknologi anjuran lebih banyak dibandingkan dengan teknologi petani. Hal ini karena adanya penggunaan input yang lengkap seperti pengapuran, pupuk organik, pupuk daun, pupuk dasar $(\mathrm{N}, \mathrm{P}, \mathrm{K})$, varietas unggul. Menurut Ar-riza et al. (2001); Santoso (2006); Riley et al. (2008) dan Dinesh et al. (2010), kondisi tersebut menyebabkann struktur tanah menjadi lebih baik. Hayati et al. (2102); Sahuri dan Rosyid (2015) menambahkan bahwa kondisi tanah yang kaya unsur hara menyebabkan pertumbuhan tanaman karet dan cabai rawit lebih baik. 


\section{Pertumbuhan dan Hasil Cabai Rawit Sebagai Tanaman Sela Karet}

Penerapan teknologi anjuran berpengaruh nyata terhadap jumlah cabang, bobot/buah, produksi buah segar/tanaman, produksi buah segar/1000 $\mathrm{m}^{2}$, kecuali tinggi tanaman dan umur panen, tetapi teknologi anjuran budidaya cabai rawit lebih baik daripada teknologi petani (Tabel 3). Melalui perbaikan teknologi budidaya cabai rawit sebagai tanaman sela karet dapat meningkatkankan hasil cabai rawit sebesar $86,44 \%$ dan pendapatan petani sebesar 101,7 $\%$. Menurut Suparwoto et al. (2012), karena adanya penggunaan input yang lengkap seperti pengapuran, pupuk organik, pupuk daun, pupuk dasar $(\mathrm{N}, \mathrm{P}, \mathrm{K})$, varietas unggul.

\section{Nilai Tambah Usahatani Cabai Rawit Sebagai Tanaman Sela Karet}

Teknologi anjuran memerlukan biaya produksi lebih besar daripada teknologi petani. Namun diimbangi oleh peningkatan hasil cabai rawit sebesar 86,44\% dan pendapatan sebesar $101,7 \%$. Pada teknologi anjuran biaya produksi sebesar 39,37\% dan biaya tenaga kerja sebesar 60,63\%, tidak menunjukkan perbedaan yang signifikan dengan teknologi petani biaya produksi sebesar 61,87 \% dan biaya tenaga kerja sebesar $38,13 \%$.
Tabel 3. Keragaan pertumbuhan dan komponen hasil cabai rawit umur 12 MST di Desa Sembawa,

\begin{tabular}{|l|c|c|c|}
\hline Parameter & Teknologi Anjuran & Teknologi Petani & Signifikasi (P) \\
\hline Tinggi tanaman (cm) & 55 & 50 & $0,261^{\text {tn }}$ \\
\hline Jumlah cabang (btg) & 6 & 3 & $0,042^{*}$ \\
\hline Umur Panen (hari) & 95 & 100 & $0,262^{\text {tn }}$ \\
\hline Bobot/buah (g) & 2,5 & 1,5 & $0,041^{*}$ \\
\hline Produksi/tanaman (kg) & 0,5 & 0,2 & $0,032^{*}$ \\
\hline Produksi/ha (ton) & 6500 & 3250 & $0,021^{*}$ \\
\hline
\end{tabular}

Keterangan: *) nyata pada $\mathrm{P}<0.05$, tn) tidak berbeda nyata

Teknologi anjuran memberikan keuntungan sebesar Rp 5.456.000,- lebih besar daripada teknologi petani sebesar Rp 2.702.700,-, karena produksi cabai lebih banyak sekitar $650,5 \quad \mathrm{~kg} \quad / 1000 \quad \mathrm{~m}^{2}$ dibandingkan dengan teknologi petani sekitar $348,9 \mathrm{~kg} / 1000 \mathrm{~m}^{2}$ ) (Tabel 4).

Penerimaan usahatani dengan teknologi anjuran Rp 9.757.500,- atau 86,44 \% lebih tinggi dan pendapatan bersih Rp 5.456.000,atau $101,7 \%$ lebih tinggi dibandingkan teknologi petani. Perbedaan besarnya penerimaan dan biaya usahatani berpengaruh terhadap $\mathrm{B} / \mathrm{C}$ ratio. Teknologi anjuran memberikan nilai $\mathrm{B} / \mathrm{C}$ sebesar 1,27 realtif lebih tinggi dibandingkan dengan teknologi petani yaitu 1,07. Hal ini menunjukkan bahwa teknologi anjuran budidaya cabai rawit sebagai tanaman sela karet secara ekonomis menguntungkan. Nilai MBCR 1,55 menunjukkan bahwa teknologi introduksi layak untuk dikembangkan (Tabel 4).

Tabel 2. Dinamika pertumbuhan lilit batang karet PB 260 dengan teknologi anjuran dan teknologi petani

\begin{tabular}{|l|c|c|c|c|c|c|}
\multirow{2}{*}{ Pola tanaman sela/Klon PB260 } & \multicolumn{6}{|c|}{ Lilit batang karet (cm)padaumur (bulan) } \\
\cline { 2 - 6 } & 4 & $\mathrm{P}$ & 8 & $\mathrm{P}$ & 12 & $\mathrm{P}$ \\
\hline Teknologi Anjuran & 4,43 & \multirow{2}{*}{$0,097^{\text {tn }}$} & 8,16 & \multirow{2}{*}{$0,026^{*}$} & 12,11 & \multirow{2}{*}{$0,021^{*}$} \\
\hline Teknologi Petani & 4,18 & & 7,8 & & 11,21 & \\
\hline \multicolumn{1}{|c|}{ Rata-rata } & 4,31 & & 7,98 & & 11,66 & \\
\hline
\end{tabular}

Keterangan: *) nyata pada $\mathrm{P}<0.05$, tn) tidak berbeda nyata 
Nilai tambah pola intercropping karet+cabai rawit adalah meningkatkan produktivitas lahan, meningkatkan pendapatan petani, dan meningkatkan pemeliharaan tanaman utama karet. Pola tanam tersebut mampu mengatasi kegagalan usahatani karet karena adanya persaingan antara tanaman karet dengan gulma. Pola tanam tersebut dapat dilakukan sepanjang tanaman karet belum menghasilkan dengan memperhatikan pola tanaman yang sesuai dengan musim.
Pola intercropping karet+cabai rawit menguntungkan baik dengan teknologi anjuran maupun dengan teknologi petani. Hal ini menunjukkan bahwa pola tanam cabai rawit sebagai tanaman sela karet di daerah pasang surut secara ekonomis menguntungkan dan layak untuk dikembangkan, terutama pada areal perekebunan karet rakyat.

Tabel 4. Analisis usahatani cabai rawit sebagai tanaman sela karet dengan luasan $1000 \mathrm{~m}^{2}$ di Desa Sembawa pada musim hujan (MH) 2014

\begin{tabular}{|c|c|c|c|c|c|}
\hline \multirow{2}{*}{ No. } & \multirow{2}{*}{ Jenis Kegiatan } & \multicolumn{2}{|c|}{ Teknologi Anjuran } & \multicolumn{2}{|c|}{ Teknologi Petani } \\
\hline & & Nilai (Rp.) & $(\%)$ & Nilai (Rp.) & $(\%)$ \\
\hline A. & Tenaga Kerja & & & & \\
\hline 1 & Pengolahan lahan + Bedengan & 521.600 & 12,13 & 326.000 & 12,89 \\
\hline 2 & Persiapan & 65.200 & 1,52 & 65.200 & 2,58 \\
\hline 3 & Persemaian dan mengisi polibeg & 260.800 & 6,06 & 130.400 & 5,16 \\
\hline 4 & Tanam & 260.800 & 6,06 & 260.800 & 10,31 \\
\hline 5 & Pembumbunan & 260.800 & 6,06 & 130.400 & 5,16 \\
\hline 6 & Pupuk dasar & 130.400 & 3,03 & 65.200 & 2,58 \\
\hline 7 & Pengendalian OPT & 130.400 & 3,03 & 130.400 & 5,16 \\
\hline 8 & Pupuk daun & 130.400 & 3,03 & 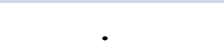 & . \\
\hline 9 & Penyiangan & 260.800 & 6,06 & 130.400 & 5,16 \\
\hline 10 & Penyiraman & 130.400 & 3,03 & 65.200 & 2,58 \\
\hline \multirow[t]{2}{*}{11} & Panen & 326.000 & 7,58 & 260.800 & 10,31 \\
\hline & Jumlah (A) & 2.608.000 & 60,63 & 1.564 .800 & 61,87 \\
\hline B & Bahan & & & & \\
\hline 1 & Benih Cabai & 400.000 & 9,30 & 250.000 & 9,88 \\
\hline 2 & Pupuk Kandang & 500.000 & 11,62 & 250.000 & 9,88 \\
\hline 3 & Urea & 120.000 & 2,79 & 60.000 & 2,37 \\
\hline 4 & TSP & 99.750 & 2,32 & 33.250 & 1,31 \\
\hline 5 & KCL & 93.750 & 2,18 & 31.250 & 1,24 \\
\hline 7 & Furadan $3 G$ & 40.000 & 0,93 & 20.000 & 0,79 \\
\hline 8 & Fungisida Dhitane M 45 & 240.000 & 5,58 & 120.000 & 4,74 \\
\hline \multirow[t]{3}{*}{10} & Polybeg $10 \times 12 \mathrm{~cm}$ & 200.000 & 4,65 & 200.000 & 7,91 \\
\hline & Jumlah (B) & 1.693.500 & $\mathbf{3 9}, 37$ & 964.500 & $\mathbf{3 8}, 13$ \\
\hline & Jumlah Total $(A+B)$ & 4.301.500 & $\mathbf{1 0 0 , 0 0}$ & 2.529.300 & $\mathbf{1 0 0 , 0 0}$ \\
\hline \multirow[t]{6}{*}{$\mathrm{C}$} & Hasil cabai (kg/1000 m2) & 650,5 & & 348,8 & \\
\hline & Harga jual (Rp/kg) & 15.000 & & 15.000 & \\
\hline & Penerimaan ( $R p)$ & 9.757 .500 & & 5.232 .000 & \\
\hline & Pendapatan (Rp) & 5.456 .000 & & 2.702 .700 & \\
\hline & $\mathrm{B} / \mathrm{C}$ ratio & 1,27 & & 1,07 & \\
\hline & MBCR & 1,55 & & & \\
\hline
\end{tabular}




\section{SIMPULAN}

Usahatani cabai rawit sebagai tanaman sela karet dengan teknologi anjuran berpengaruh sangat nyata terhadap pertumbuhan lilit batang karet, jumlah cabang, bobot/buah, produksi buah segar/tanaman, produksi buah segar $/ 1000 \mathrm{~m}^{2}$, kecuali tinggi tanaman dan umur panen, tetapi teknologi anjuran budidaya cabai rawit lebih baik daripada teknologi petani. Produksi buah segar sebesar 650,5 kg/1000 m² (konversi 6,5 ton/ha) lebih tinggi dibandingkan teknologi petani sebesar 348,9 $\mathrm{kg} / 1000 \quad \mathrm{~m}^{2}$ (konversi 3,5 ton/ha). Keuntungan yang diperoleh usahatani cabai rawit dengan penerapan teknologi anjuran sebesar Rp 5.456.000/1000 $\mathrm{m}^{2}$ lebih besar daripada teknologi petani Rp 2.704.200/1000 $\mathrm{m}^{2}$ dengan nilai $\mathrm{B} / \mathrm{C}$ ratio 1,27 dan usahatani tersebut layak untuk dikembangkan dengan nilai MBCR 1,55.

\section{UCAPAN TERIMA KASIH}

Ucapan terimakasih kepada Ir. M. Jahidin Rosyid, MS sebagai peneliti utama yang telah memberikan masukan dan saran dalam penulisan makalah ini.

\section{DAFTAR PUSTAKA}

Acquaah, G. 2005. Principles of Crop Production. Theory, Technique, and Technology. Pearson, Prentice Hall, New Jersey.

Adri, Firdaus, Mugianto, Yardha dan Syari Edi. 2005. Laporan Akhir Kegiatan Pengkajian Sistem dan Usaha Agribisnis Berbasis Komoditas Karet. Balai Pengkajian Teknologi Pertanian (BPTP) Jambi.

Anwar, K. 2001. Manajemen dan Teknologi Budidaya Karet. Pusat Penelitian Karet Medan.

Ar-riza, I.D. Nazemi, dan M. Alwi. 2001. Peranan Glifosat Dalam Pengendalian Gulma dan Suksesi Gulma pada
Pertanaman Padi Intercrop dengan Tanman Karet di Lahan Kering Masam. Prosiding Konferensi Nasional XV, Himpunan Ilmu Gulma Indonesia. Suroto, D., A. Yunus, E. Purwanto, Wartoyo, dan Supriyono (ed), Surakarta, 17-19 Juli 2001. hlm. 496-503.

Badan Pusat Statistik. 2011. Luas panen, produksi dan produktivitas cabai tahun 2010. Diakses dari http://www.bps.go.id. Html.

Dinesh, R., V. Srinivasan, S. Hamza, A. Manjusha. 2010. Shortterm incorporation of organic manures and biofertilizers infuences biochemical and microbial characteristics of soils under an annual crop turmeric (Curcuma longa L.). Bioresource Technol. 101:4697-4702.

Gomez, K.A and A.A. Gomez. 1995. Prosedur Statistik untuk Penelitian Pertanian. Terjemahan dari: Statistical Procedures for Agricultural Research. Penerjemah: E. Sjamsudin dan Baharsjah. Penerbit Universitas Indonesia. Jakarta. 698 hal.

Hayati, E., T. Mahmud, dan R. Fazil. 2012. Pengaruh jenis pupuk organik dan varietas terhadap pertumbuhan dan hasil tanaman cabai (Capsicum annum L.). J. Floratek. 7, $173-181$.

Moekasan, T.K., L. Prabaningrum, N. Gunadi, W. Adiyoga, A.P. Everaarts, H. De Putter, M. van de Staij, W.van Dijk, H. Schepers, dan F. van Koesveld. 2011. Pengelolaan Tanaman Terpadu pada Budidaya Cabai Merah Sistem Tumpang Gilir dengan Bawang Merah. Pusat Penelitian dan Pengembangan Hortikultura, Badan Penelitian dan Pengembangan Pertanian Republik Indonesia. Jakarta.

Prasetyo, E. I. Sukardjo dan H. Pujiwa. 2009. Produktivitas lahan dan nkl pada tumpang sari jarak pagar dengan tanaman pangan. Jurnal Akta Agrosia, 12(1), 51 - 55.

Pribadi, E.K. 2003. Program Pemberdayaan Masyarakat Petani Melalui Peningkatan Usaha Tanaman Cabai Kasus Desa Air 
putih Kecamatan Bengkalis Kabupaten Bengkalis. Program Studi Pengembangan Masyarakat. Program Pasca Sarjana Institut Pertanian Bogor.

Riley, H., R. Pommeresche, R. Eltun, S. Hansen, A. Korsaeth. 2008. Soil structure, organic matter and earthworm activity in a comparison of cropping systems with contrasting tillage, rotations, fertilizer levels and manure use. Agric. Ecosyst. Environ, 124, 275-284.

Rodrigo, V.H.L., C.M. Stirling, Z. Teklehaimanot, A. Nugawela. 2001. Intercropping with banana to improve fractional interception and radiation-use efficiency of immature rubber plantations. Field Crops Res, 69: 237-249.

Rodrigo, V.H.L., T.U.K. Silva, E.S. Munasinghe. 2004. Improving the spatial arrangement of planting rubber (Hevea brasiliensis Muell. Arg.) for long-term intercropping. Field Crops Research, 89(2): 327-335.

Rosyid, M.J. 2007. Pengaruh tanaman sela terhadap pertumbuhan karet pada areal peremajaan partisipatif di Kabupaten Sarolangun, Jambi. J. Penelitian Karet, 25(2), 25-36.

Sahuri dan M.J. Rosyid. 2015. Analisis usahatani dan optimalisasi pemanfaatan gawangan karet menggunakan cabai rawit sebagai tanaman sela. Warta Perkaretan, 34(2): 77-88.

Santoso, B. 2006. Pemberdayaan Lahan Podsolik Merah Kuning dengan Tanaman Rosela (Hibiscus sabdariffa L.) di Kalimantan Selatan. J. Perspektif, 5(1), 112.

Snoeck, D., R. Lacotea, J. Kéli, A. Doumbiac, T. Chapuset, P. Jagoretd, E. Goheta. 2013. Association of hevea with other tree crops can be more profitable than hevea monocrop during first 12 years. Industrial Crops and Products, 43: 578-586.
Suparwoto, Waluyo dan Jumakir. 2012. Peningkatan pendapatan petani cabai merah melalui perbaikan teknologi usahatani di Kabupaten Banyuasin, Sumatera Selatan. Jurnal Pembangunan Manusia, 6(1), 11-11.

Syawal, Y. 2010. Interaksi Tanaman dengan Gulma. Unsri Press. Palembang.

Syukur, M., S. Sujiprihati, J. Koswara, dan Widodo. 2007. Pewarisan ketahanan cabai (capsicum annuum 1.) terhadap antraknosa yang disebabkan oleh Colletotrichum acutatum. Buletin Agronomi, 35(2), 112 117.

Weifu, L., Z. Zhongyu, H. Shoufeng. 1999. A review and prospect of intercropping in rubber plantation in China. Chinese Journal Of Ecology. 1999-01:S344.2,S576 [Internet]. [diunduh 2 Oktober 2016]. Tersedia pada: http://en.cnki.com.cn/Article_en/CJFDTO TAL-STXZ901.009.htm.

Wibawa, G dan M.J. Rosyid. (1995). Peningkatan produktivitas padi sebagai tanaman sela karet. Warta Perkaretan, 14(1), 40-46.

Wibawa, G., M.J. Rosyid, dan A. Gunawan. 2006. Pola Tumpangsari Pada Perkebunan Karet. Pusat Penelitian Karet Balai Penelitian Sembawa. 126 hal.

Xianhai, Z., C. Mingdao, dan L. Weifu. 2012. Improving planting pattern for intercropping in the whole production span of rubber tree. African Journal of Biotechnology, 11(34): 8484-8490.

Zainol, E., A.W. Mahmud, dan M.N. Sudin. 1993. Effects of intercropping systems on surface processes in an acid ultisol 2 . changes in soil chemical properties and their influence on crop performance. $J$. nat. Rubb. Res, 8(2):124-136. 
